\title{
The Presidential Campaign Hotline: Its Use in Libraries
}

\section{By Ellen Sutton}

Former Social Sciences Reference Librarian

University of North Carolina at Chapel Hill

\section{and Margaret Jackson}

Social Sciences Reference Librarian

University of North Carolina at Chapel Hill
The Hotline (until just recently called the Presidential Campaign Hotline), an online daily current awareness service, gathers and distributes the latest available information on political campaigns and candidates. It is produced by the American Political Network (APN) of McLean, Virginia. Begun on September 15, 1987, the Hotline's purpose is to furnish a central means by which reporters and political analysts can exchange or simply obtain local and regional news surrounding the upcoming presidential election. Formerly, this type of information was exchanged by political insiders making telephone calls to each other or by reading or viewing others' news and editorial features when they appeared in the standard media.

Reporters may call in news to the Hotline after receiving editorial approval from their own organization, so responses to the news or opinion often appears the next day, rather than several days later. The Hotline's sources of information include the candidates' campaign organizations, political analysts retained by the APN, national or regional newspapers, television networks, and wire services. According APN's Andrew Crosby, the Hotline's base of subscribers has grown from the original group of reporters and analysts to include political action committees, corporations, foreign embassies, universities, and private individuals.

The Business Administration/Social Sciences Reference Department at Davis Library at the University of North Carolina began subscribing to the Hotline in October 1987. The daily updates of the Hotline are printed and housed as a part of the reference collection. Subsequently, the Hotline has become a significant resource to members of the university community.

\section{Background}

The American Political Network is the creation of Douglas Bailey, a Republican political consultant, and Roger Craver, a Democratic direct mail expert. Other members of the staff of the American Political Network have experience with political campaigns or administrations and represent a balance of political affiliations. The Hotline's policy is to provide a balanced account and representation of the political events and candidates. Each Presidential campaign organization is allowed 200 unedited words per day in the Campaign Reports section of the Hotline.
The Hotline runs approximately 20 pages in length and is printed in a readable format which includes daily highlights, a table of contents, major news stories on the campaigns themselves or on news events surrounding the campaigns, reports from the campaign organizations, latest poll information in tabular format, and each candidate's "media market schedule" (which in recent months has been curtailed to a handful of lines as the presidential candidates have been weeded out). Following each item within a section, abbreviated source data is provided. For example, "(CBS, $2 / 22)$," "(N.Y. Times, 2/23)," etc. "Hotline Highlights," which represents the major news stories of the day covered by numerous reporters, may refer the reader to "(L.A. Times, Baltimore Sun, USA Today, N.Y. Times, Washington Post, Philadelphia Inquirer, 2/22, See [Hotline item] \#3).” Although the Hotline is inferior to the Wall Street Journal or New York Times bibliographic elements which include page and column in addition to date, one can locate the article with a bit of effort.

Originally intended to run from October 15, 1987, through March 1989, the Hotline is now scheduled to continue indefinitely, shifting its focus to U.S. Senate and House races and other regional contests. As the field of Presidential candidates has narrowed, more attention has been devoted in recent months to Senatorial elections. In addition to news briefs on targeted Senate races, reports from various campaigns are now included. In the future, APN may concentrate on major gubernatorial and mayoral races as well as possible inclusion of Supreme Court activities.

\section{Searching the Hotline}

Subscribers to the Hotline pay varying rates, depending on their status and level of contribution to the Hotline. The Hotline is evolving in other ways as it matures: in January of 1988, the APN announced the creation of a new "Hotline database," searchable via CompuServe. The database could be searched by candidate, by date, major sections (like the "Poll Update" section) and a limited number of keywords such as "Bork" or "abortion" (an appendix lists the keywords), which can be requested in combination (Bork and abortion). This searching option was an extension of the regular subscription but has now been dropped indefinitely. Should the user exceed the monthly time al- 
lotment for downloading of approximately 3.5 hours, a charge of $\$ 50$ per hour is incurred.

Until the development of the searchable database, one could not retrieve a given day's Hotline after the next day's had been loaded online. This searching capability is now available through a more sophisticated database, via the Dialcom computer network. The Dialcom database, which is "searchable by virtually any word, subject, or combination," was announced in the APN promotional literature in January and became available in early spring.

As of June 1988, access to the Hotline is obtained in several ways. The most common is to subscribe to it directly from the APN office and receive it through a telecommunications utility, primarily CompuServe. APN offers varying subscription rates for non-profit (such as college and university libraries) and profit-making organizations. A second way is via Dialcom, a subsidiary of British Telecommunications based in Rockville, Maryland. Dialcom is a database vendor which has offered the Hotline under the code PEN ("Political Election News") since February 10, 1988.

PEN carries a database surcharge of $\$ 65$ per hour plus an average connect fee of $\$ 14$ per hour. It includes the Hotline from its inception in September of 1987. Each day's update is available at 9:00 a.m. PEN can be searched as a retrospective database, using Boolean operators.

A third source is NewsNet, a database vendor whose search system is more sophisticated than the keyword searching Dialcom offers, but provides coverage of only February 1 to the present. Subscribers to NewsNet may read the Hotline each day after it becomes available at 9:00 a.m. Currently, costs for the NewsNet service include a $\$ 15$ monthly subscription fee for telecommunications and documentation and an $\$ 84$ per hour full-text royalty charge to read the daily Hotline. Finally, one can obtain the Hotline database by section directly through CompuServe. Coverage is same day only. The searcher is limited to searching by section using the CompuServe database capabilities. Additionally, library users with access to ALANET also have access to the Hotline. ALANET is also searched via the Dialcom system.

\section{Use of the Hotline at UNC}

Faculty and other instructors at UNC in the Departments of Radio, Television, and Motion Pictures, Political Science, Journalism, and Speech Communication have expressed an interest in the Hotline either for instructional purposes or their own research. The influence and recommendations of several members of the faculty of these departments was instrumental in the Library's decision to subscribe to the Hotline. Special research funds were used for the subscription and the decision to renew it will be reviewed annually.
One research project involving the Hotline concerns the effect the Hotline may be having on the reporting of political news-the communication behavior of reporters and political analysts as well as the effect on the content of the reporting. One theory being explored is that this political news may become more homogenous and less regional or reflective of individual analysts' original opinion now that opinion and reaction are so immediately and centrally available. In Newsweek, as early as November 2, 1987, Mickey Kaus and Eleanor Clift describe the pattern of the convergence of opinion on the part of reporters and political analysts, citing the phenomenon of "pack journalism" in which reporters rely on computerized, rather than firsthand information.

Thus far, the Hotline has been used at Davis Library only in its static form, as a daily printout, and not as a computer-searchable database. This is due in part to the APN's timing and delays in producing and documenting the database. The searchable aspects of the Hotline have not yet been widely promoted at UNC.

The Hotline is downloaded to disk and printed out after reformatting using a word processing program in the mornings, usually shortly after it is made available at approximately 10:00 a.m. This pertains to weekday mornings only, as it is not issued weekends or holidays. The Hotline can be downloaded in approximately seven to nine minutes. An archival disk and a backup disk are kept in BA/SS for future reference. The current day's printout is kept at the reference desk. Patrons must leave an identification card to take it from the desk area.

Previous issues are kept in a publicly accessible file cabinet until recently. A number of printouts were removed from the collection and not returned, which had to be reprinted from disk. The printouts were moved to a cabinet behind the reference desk, from which patrons may check them out. Only one week's Hotlines (five files) are placed on a single floppy disk, and disks are copied by request if the patrons furnish their own disks. Thus, each disk is a definable unit, and is more easily used by faculty assigning a given week's news to students.

\section{Conclusion}

The Hotline has proven to be an important source of information at Davis Library. Continued accumulation of daily political data can serve a useful purpose as a historical resource to scholars in various disciplines, particularly those involving communications or American political behavior. The evolution of political campaigns and the effect of media on these campaigns can be studied. Additionally, the daily downloaded information serves the obvious purpose of keeping the university community informed about a wide variety of information concerning the election of its officials. 
With APN's plans to shift the focus of the Hotline to broader political coverage, it should continue to be an option for subscribers. By summarizing and analyzing current political events, it provides the most up-to-date source for a wide variety of users. We anticipate that increasingly it will become a standard source for students in political science and related disciplines.

\title{
The library newsletter:
}

\section{Is it for you?}

\author{
By Sylverna Ford \\ Assistant to the Director of University Libraries \\ Carnegie Mellon University
}

\section{Newsletters can be a vital public relations tool for the} library administration.

D uring the Spring of 1984, a decision was made to start a newsletter at the University Libraries of Carnegie Mellon. The first issue of the newsletter was produced in October of that year. Since that time a total of eleven issues of the newsletter have been produced. For nearly three years the newsletter remained under the editorship of the original editor. In the summer of 1987 , I inherited the responsibility for editing Resources: The CMU Libraries' News. Editing a newsletter was a new experience for me and I found that I had many questions for which there were no immediate answers.

I spent several days considering the hows and whys of producing the newsletter. Turning to the professional literature for guidance I learned, to my chagrin, that there was not much available. Little has actually been written on producing a library newsletter; certainly the necessary planning process has not been addressed. The articles that have been written are primarily geared to commercially produced, for-profit publications. This dearth of information prompted me to document my own experience. Out of that grew a working guide which in time evolved into the guidelines and specifications for the newsletter of the Carnegie Mellon University Libraries.

\section{Why a newsletter?}

In the commercial markets, the newsletter seems to be emerging as the medium of the new era. There are newsletters addressing almost any subject you can think of. ${ }^{1}$ There are thousands of newsletters being produced today; they range in price from free to hundreds of dollars per year-and they keep coming. Newsletter production is a business in its own right. What does the newsletter have to offer that makes it so attractive in the marketplace? What is the impetus behind the increased interest in this form of publication? Simply

\footnotetext{
1"Starting Your Own Newsletter," Changing Times 40 (April 1986): 77.
} 